Canadian University Music Review

Revue de musique des universités canadiennes

\title{
ALBERT ROUSSEL. Lettres et autres Écrits. Textes présentés et annotés par Nicole Labelle. Paris : Flammarion, coll. Harmoniques, 1987, 361 p.
}

\section{François de Médicis}

Volume 9, numéro 1, 1988

URI : https://id.erudit.org/iderudit/1014930ar

DOI : https://doi.org/10.7202/1014930ar

Aller au sommaire du numéro

Éditeur(s)

Canadian University Music Society / Société de musique des universités canadiennes

ISSN

0710-0353 (imprimé)

2291-2436 (numérique)

Découvrir la revue

Citer ce compte rendu

de Médicis, F. (1988). Compte rendu de [ALBERT ROUSSEL. Lettres et autres Écrits. Textes présentés et annotés par Nicole Labelle. Paris : Flammarion, coll. Harmoniques, 1987, 361 p.] Canadian University Music Review / Revue de musique des universités canadiennes, 9(1), 206-207.

https://doi.org/10.7202/1014930ar

All Rights Reserved (C Canadian University Music Society / Société de musique des universités canadiennes, 1988
Ce document est protégé par la loi sur le droit d'auteur. L'utilisation des services d'Érudit (y compris la reproduction) est assujettie à sa politique d'utilisation que vous pouvez consulter en ligne.

https://apropos.erudit.org/fr/usagers/politique-dutilisation/ 
soulignée ici, mais trop peu admise dans les études anthropologiques, met encore une fois à jour la nature des propos des auteurs.

L'interprétation marxiste des faits marquants de l'histoire du bandonéon n'en est pas moins claire. Le choix des termes (par exemple : prolétariat, système de production, production de biens matériels, etc.), la juxtaposition adroite de certains faits, l'ordre de présentation des événements contribuent à exposer le déroulement de l'histoire dans une perspective marxiste. Toute histoire tient au fil que l'auteur a choisi de tisser pour la rendre. Que l'on soit d'accord ou non avec les mises en relation, le choix de ce qui est la cause et de ce qui est l'effet, la description du théâtre où se joue le bandonéon fourmille d'informations.

Le Bandonéon depuis le Tango n'est pas seulement un ouvrage indispensable pour tout étudiant de musique latino-américaine mais aussi pour tout autre chercheur désireux de trouver une approche différente et originale de l'écriture ethnographique. Qui plus est, c'est une oeuvre littéraire remarquable, où l'humour subtil côtoie la passion de l'écriture.

Jocelyne Guilbault

ALBERT ROUSSEL. Lettres et autres Écrits. Textes présentés et annotés par Nicole Labelle. Paris : Flammarion, coll. Harmoniques, 1987, 361 p.

Depuis la croisade des compositeurs sérialistes post-weberniens contre la musique de l'entre-deux-guerres, les musicologues avaient prudemment négligé une époque aussi controversée. Le livre Lettres et Écrits d'Albert Roussel témoigne du regain d'intérêt pour cette période encore mal connue et d'un effort pour porter sur elle un jugement plus objectif. Car c'est toute une époque de l'histoire musicale française qui revit à travers les écrits de Roussel : époque mouvementée où s'affirme le Groupe des Six, où domine la personnalité de Stravinsky, où s'affrontent la Société Nationale de Musique et la Société de Musique Indépendante, époque éclatée où les compositeurs se laissent charmer par les sonorités envoûtantes du jazz, où triomphent le néo-classicisme, le machinisme, la polytonalité, etc.

Ce livre se recommande par l'abondance et la qualité des textes réunis, pour la plupart encore inédits. L'intérêt musical d'abord, biographique et psychologique ensuite, a présidé au choix des lettres dans la première partie et à la sélection des écrits dans la seconde. La correspondance suit l'ordre chronologique et se divise en cinq chapitres délimitant cinq périodes de la vie ou de l'oeuvre de Roussel (établies par Nicole Labelle) : l'apprentissage, les premiers chefs-d'oeuvre, la guerre, la maturité, la sérénité. Un résumé biographique et une liste d'oeuvres composées durant la période considérée précèdent chaque chapitre. 
Sur les soixante-trois textes que Nicole Labelle a compulsés et dont on peut consulter la bibliographie en fin de volume, les trente-huit écrits retenus sont répartis dans trois sections thématiques, suivant chaque fois l'ordre chronologique : les oeuvres et leur esthétique, portraits de musiciens, esthétique et pédagogie musicales. Le texte est soumis aux exigences de l'édition critique, il comporte d'abondantes notes. La minutie du travail critique sera très utile au chercheur, sans gêner le lecteur non spécialisé.

La sympathique figure du musicien est caractérisée par une grande honnêteté, une conscience aiguë de sa valeur mais dénuée de toute prétention, un jugement lucide, sans parti-pris ni complaisance. Il a occupé une place privilégiée dans la musique de son pays, comme le souligne cette phrase de Messiaen : "Toute la musique française me semble aujourd'hui polarisée par Albert Roussel, celui de la Suite en fa et des Symphonies, et par le premier Stravinsky" (p. 321n.).

Son époque s'anime et revit sous sa plume avec, néanmoins, ce recul, cette distance que lui donne sa qualité peut-être la plus essentielle, son indépendance. Il reste en marge de toutes les modes à une époque où se multiplient les mots d'ordre, où foisonnent les groupuscules : le Groupe des Six, l'école d'Arcueil, l'école de Paris. Il conserve aussi son indépendance face à la reconnaissance officielle, déclinant, comme Ravel (mais sans fracas), la Légion d'honneur. Réformé durant la guerre, il manifeste un courageux patriotisme en demandant de servir sous les drapeaux ; mais il n'hésite pas à condamner les expressions de nationalisme dégénéré, comme cette tentative d'empêcher l'exécution de la musique germanique en France.

Les grandes questions de l'heurre ne le laissent pas indifférent. Lorsque Stravinsky relance le vieux débat sur la nature expressive de la musique (on connaît la phrase célèbre "je considère la musique, par son essence, impuissante à exprimer quoi que ce soit"), le compositeur français adopte un point de vue nuancé qui se rapproche de celui de Hanslick. Certaines questions gardent toute leur actualité : la survie de l'opéra, la crise de la notation musicale. Nicole Labelle commente de la façon suivante la condamnation de l'atonalité par Roussel : " $\mathrm{Si}$ on a pu croire que Roussel se trompait, l'évolution récente des langages musicaux tendrait à laisser penser qu'il pouvait avoir raison puisque plusieurs compositeurs sembleraient avoir déserté ce système d'écriture" (p. 13).

Ainsi, à travers l'histoire d'un homme et d'une époque, surgissent des préoccupations toujours très actuelles. C'est donc un livre qui peut légitimement prétendre rejoindre un large public par la qualité de son contenu et son accessibilité, et par sa rigueur de présentation. On déplorera seulement le prix prohibitif qui devrait en limiter la diffusion. Ceux qui se seront plu à la lecture pourront la prolonger dans la monographie sur Roussel que prépare actuellement Nicole Labelle. 